\title{
The Favorite-Longshot Bias: An Overview of the Main Explanations
}

\author{
Marco Ottaviani* $^{*} \quad$ Peter Norman Sørensen $^{\dagger}$
}

November 2007

\begin{abstract}
In betting markets, the expected return on longshot bets tends to be systematically lower than on favorite bets. This favorite-longshot bias is a widely documented empirical fact, often perceived to be an important deviation from the market efficiency hypothesis. This chapter presents an overview of the main theoretical explanations for this bias proposed in the literature.
\end{abstract}

${ }^{*}$ London Business School and Kellogg School of Management, Northwestern University, 2001 Sheridan Road, Evanston, IL 60208-2013. Phone: +1-843-467-0684. Fax: +1-843-467-1777. E-mail: m-ottaviani@northwestern.edu. Web: http://faculty.london.edu/mottaviani.

$\dagger$ Department of Economics, University of Copenhagen, Studiestræde 6, DK-1455 Copenhagen K, Denmark. Phone: +45-3532-3056. Fax: +45-3532-3000. E-mail: peter.sorensen@econ.ku.dk. Web: http://www.econ.ku.dk/sorensen. 


\section{Introduction}

A central theme of the literature on betting is the occurrence of the favorite longshot bias (FLB). The first documentation of this bias is attributed to Griffith (1949), who observed that horses with short odds (i.e., favorites) yield on average higher returns than horses with long odds (i.e., longshots). This means that market probabilities of longshots (obtained from market prices) overpredict on average their empirical probabilities (computed from race outcomes). At the other end of the spectrum, the market probabilities of favorites tend to underpredict their empirical probabilities. This chapter presents an overview of the wide range of theories proposed in the literature to explain this bias.

Betting markets have attracted a lot of attention by economists because they provide a particularly appealing environment for testing theories of market efficiency. ${ }^{1}$ First, the outcomes in these markets are publicly observed at a pre-specified time -instead, in regular financial markets the uncertainty about asset values is typically resolved only in the long run, if ever. Second, in the case of betting the realized outcomes are exogenous to the trading process and the resulting prices - while the intrinsic value can easily be affected by market prices in more traditional financial settings. Third, parimutuel betting markets are particularly suited to testing for market efficiency because prices there are not set (and so potentially mis-aligned) by individual market makers. By placing a parimutuel bet on an outcome, a participant demands a share of all the funds supplied by the other participants conditional on the realization of that outcome and, contemporaneously, supplies funds to all the other participants if that outcome is not realized.

Indeed, most of the empirical literature has focused on parimutuel markets, in which the money bet on all outcomes is pooled and then shared proportionally among those who picked the winning outcome, after a fractional sum is deducted for taxes and expenses. If the market were efficient, all the bettors were risk neutral, and they shared the same belief about the outcome, the final distribution of parimutuel bets should be directly proportional to the market's assessment of the horses' chances of winning. This is because the gross expected payoff of a bet on an outcome is equal to the ratio of the outcome's probability to the proportion of bets placed on that outcome. If the fraction of money bet on each outcome is equal to its probability, the expected payoffs would then be equalized across

\footnotetext{
${ }^{1}$ A clear drawback of betting markets is that traders may be motivated by recreational objectives that we expect to play less of a role in regular financial markets.
} 
all outcomes.

The FLB is often perceived to be an important deviation from the market efficiency hypothesis. A voluminous empirical literature (surveyed, among others, by Thaler and Ziemba (1988), Hausch and Ziemba (1995), Sauer (1998), and Jullien and Salanié (2008)) has documented the extent of this bias across different events, countries, and market structures. Despite the presence of a fair amount of variation in the extent and sometimes the direction of the bias, the FLB has emerged as an empirical regularity. While the initial literature focused on parimutuel markets, the FLB is also observed (often to a greater extent) in markets dominated by bookmakers.

In a short paper that appears to have gone completely unnoticed, Borel (1938) presented the first theoretical analysis of optimal betting behavior and equilibrium in the parimutuel game. ${ }^{2}$ This remarkable paper foretells a number of the essential elements of the theories developed later in the literature:

- First, Borel introduced the problem and defined the equilibrium in the context of betting on the sum obtained rolling two dices, for which players naturally share common (or objective) probability assessments: "This game will be equitable, if the total amount bet on each point is proportional to the probability of obtaining that point; but there appears to be no a priori reason for this condition to be realized on its own." ${ }^{3}$ He then discussed informally the forces that bring the system to equilibrium in the context of this game.

- Second, Borel described how parimutuel odds adjust against the bettor and then determined the optimal amount a bettor should place on one of two outcomes to maximize the expected return, given an initial distribution of bets. ${ }^{4}$ He then considered the case of a sequence of players who make optimal bets, after observing the amounts placed in the past. He noted that the amounts bet (in the subgame-perfect equilibrium) make the game asymptotically equitable.

- Third, Borel modeled a parimutuel market and two classes of strategic bettors with heterogeneous subjective probability beliefs about the outcome of a race between two

\footnotetext{
${ }^{2}$ We searched extensively for references to this article, but did not find any.

${ }^{3}$ This equilibrium notion is the main benchmark with respect to which the FLB is defined in the literature.

${ }^{4}$ This problem is further explored by Borel (1950) and later generalized by Isaacs (1953). See Section 4.
} 
horses. In each class, there are two bettors who share the same probability belief about the race outcome, but beliefs are different for bettors belonging to the two classes. Borel characterized the (Nash) equilibrium of this game and concluded with an informal discussion of the timing incentives. ${ }^{5}$

Over the last seven decades, a number of theories have been advanced to explain the FLB. In this chapter we review the main theoretical explanations for the FLB proposed thus far in the literature, in order of their chronological development:

1. Misestimation of probabilities (Section 3): The bias can be due to the tendency of individual decision makers to overestimate small probability events. This explanation was initially advanced by Griffith (1949), who suggested that there is a psychological bias that leads individuals to subjectively ascribe too large probabilities to rare events.

2. Market power by informed bettors (Section 4): A monopolist bettor who bets large amounts should not equate the expected return on the marginal bet to zero, since this would destroy the return on the inframarginal bets. If this large bettor has unbiased beliefs and bets optimally on the favorite, the FLB results. This explanation follows from the analysis of Isaacs (1953).

3. Preference for risk (Section 5): If individual bettors love risk or skewness, they are willing to accept a lower expected payoff when betting on longshots. This explanation was articulated by Weitzman (1965), who also estimated a model with a representative individual bettor who loves risk, and so is willing to give up a larger expected payoff when assuming a greater risk on a longshot with longer odds.

4. Heterogeneous beliefs (Section 6): If bettors have heterogeneous beliefs, the market probabilities resulting in the parimutuel system tend to be less extreme than the bettors' median belief. This theory, formulated by Ali (1977), can explain the FLB if one is prepared to assume that the bettors' median belief is equal to the empirical probability.

\footnotetext{
${ }^{5}$ As explained below in Section 10.1, parimutuel betting is a version of Cournot's quantity competition game.
} 
5. Market power by uninformed bookmakers (Section 7): For fixed odds betting markets, Shin (1991 and 1992) explained the favorite-longshot bias as the response of an uninformed bookmaker to the private information possessed by insiders.

6. Limited arbitrage by informed bettors (Section 8): The FLB results when price-taking (and risk-neutral) bettors possess superior information, since the amount of arbitrage is limited by the presence of the track take and the inability to place negative bets. This explanation was proposed by Hurley and McDonough (1995).

7. Simultaneous betting by partially informed insiders (Section 9): In parimutuel markets, the bias arises if privately informed bettors place last-minute bets without knowing the final distribution of other bettors' bets. This explanation is due to Ottaviani and Sørensen (2006), who derived the bias in a parimutuel market as the result of bets placed simultaneously.

We begin by introducing the notation in Section 2 and then proceed to develop the explanations. Given that these explanations have similar qualitative implications about the FLB, it has proven difficult for empiricists to distinguish between the alternative theories. To reach some tentative conclusions about the relative merits of the different explanations, the literature has resorted mostly to test the ability of theories to simultaneously explain the FLB as well as other regularities regarding the dynamic adjustment in market prices and the timing of bets. While a comparison of the performance of the different explanations is well beyond the scope of this chapter, we conclude in Section 10 by giving an indication of some additional theoretical predictions regarding the timing of bets.

\section{Notation}

Given our aim at presenting the explanations in the simplest possible setting, we focus on the case with two outcomes. We denote the outcome (corresponding to the winning horse) by $x \in \mathcal{X}=\{1,2\}$. We denote bettors by $n \in \mathcal{N}=\{0,1, \ldots, N\}$, where $n=0$ represents all outsiders and bettors with index $n \geq 1$ are strategic insiders. Bettors may have different prior beliefs. For convenience, we denote bettor $n$ 's prior belief for outcome 1 by $q_{n}=\operatorname{Pr}(x=1)$. When allowing for private information, bettor $n$ 's signal is $s_{n} \in \mathcal{S}$, resulting in posterior belief $r_{n}=\operatorname{Pr}\left(x=1 \mid s=s_{n}\right)$. 
The amount placed by bettor $n$ on horse $x$ is $b_{n}(x)$ and the total amount placed on $x$ is $b(x)=\sum_{\mathcal{N}} b_{n}(x)$. The total bets placed on $x$ by the opponents of bettor $n$ are $b_{-n}(x)=b(x)-b_{n}(x)$. Total overall bets are $B=\sum_{\mathcal{X}} b(x)$ (also known as the "pool"), while total bets placed by the opponents of bettor $n$ are $B_{-n}=\sum_{\mathcal{X}} b_{-n}(x) .{ }^{6}$ The track take, $\tau$, is a percentage subtracted from the pool for taxes and expenses. ${ }^{7}$

The parimutuel odds are then $\rho(x)=[(1-\tau) B-b(x)] / b(x)$, so that every bet on horse $x$ wins $1+\rho(x)=[(1-\tau) B] / b(x)$ if $x$ is realized. The parimutuel system results in the market probability $m(x)=(1-\tau) /[1+\rho(x)]=b(x) / B$, with $m=m(1)$ for convenience. We denote the objective (or empirical) probability by $p(x)$, with $p=p(1)$.

\section{Misestimation of Probabilities}

When Griffith (1949) uncovered the FLB, he referred to a simple psychological explanation based on biases in the market participants' assessment of the probability attached to the different outcomes. For the purpose of our illustration with two outcomes, assume that all bettors attribute a perceived probability equal to $\pi(p)$ to an outcome with objective probability $p$. The key assumption of the theory is that bettors overestimate the chance of unlikely outcomes but underestimate the chance of likely outcomes: $1 / 2>\pi(p)>p$ for $p<1 / 2$ and $1 / 2<\pi(p)<p$ for $p>1 / 2$.

Let $p$ be the objective probability of horse 1 and $\pi(p)$ the perceived probability. The perceived expected net monetary payment (or payoff) of a bet on horse 1 is

$$
\pi(p)\left(-1+\frac{1}{m}\right)+[1-\pi(p)](-1)=\frac{\pi(p)}{m}-1 .
$$

Similarly, the perceived expected payoff of a bet on horse 2 is

$$
\pi(1-p)\left(-1+\frac{1}{1-m}\right)+[1-\pi(1-p)](-1)=\frac{\pi(1-p)}{1-m}-1 .
$$

In equilibrium, the perceived expected payoffs of the two bets must be equal,

$$
\frac{\pi(p)}{m}=\frac{\pi(1-p)}{1-m}
$$

\footnotetext{
${ }^{6}$ Note that $b_{-0}$ is different from $b_{0}$, and similarly $B_{-0}$ is different from $B_{0}$.

${ }^{7}$ The presence of a positive track take plays a key role in the explanation proposed in Section 8. To simplify our derivations, we set $\tau=0$ when presenting most of the other explanations.
} 


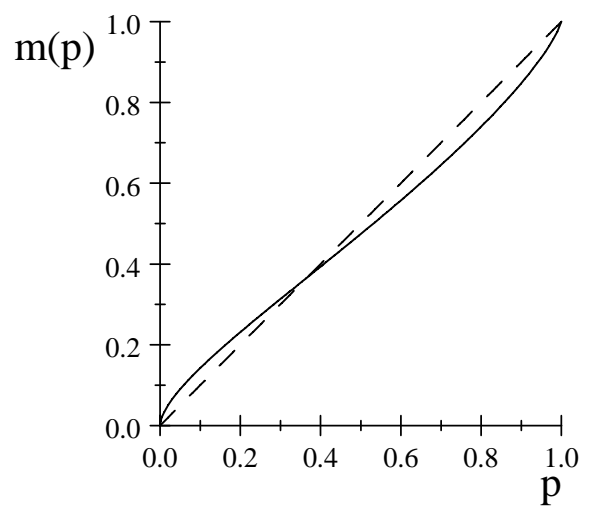

Figure 1: Market probability against objective probability for $a=.8$. The dashed line is the diagonal.

Suppose that $p>1 / 2>1-p$. Then $p>\pi(p)>1 / 2>\pi(1-p)>1-p$ by the key assumption of the theory. Hence,

$$
\frac{p}{1-p}>\frac{m}{1-m}=\frac{\pi(p)}{\pi(1-p)}>1 .
$$

We can conclude that the FLB arises:

Proposition 1 If $\pi(p)<p$ for $p>1 / 2$ and $\pi(p)>p$ for $p<1 / 2$, the market probability of the favorite (respectively longshot) is lower (respectively higher) than its objective probability: if $p>1 / 2$, then $1 / 2<m<p$ (respectively if $p<1 / 2$, then $p<m<1 / 2$ ).

We illustrate this explanation by using Prelec's (1998) weighting function with $a<1$,

$$
m=\pi(p)=\exp \left[-(-\ln p)^{a}\right]
$$

where $m$ is the market probability and $p$ is the objective probability. ${ }^{8}$ Figure 1 plots $\pi(p)$ for $a=.8$.

\section{Market Power by Informed Bettors}

Isaacs (1953) advanced an explanation for the FLB based on optimal betting behavior by a large privately informed bettor. This explanation is based on the fact that the more money

\footnotetext{
${ }^{8}$ As evident from Figure 1, Prelec's function has $\pi(\hat{p})=\hat{p}$ for a threshold $\hat{p}=1 / e$ somewhat below $1 / 2$. The spirit of the FLB is preserved, nevertheless.
} 
this bettor places on a horse, the lower the odds that result in the parimutuel system. Then, an informed bettor would want to limit the amount bet in order to maximize the profits made.

To understand why additional bets on a horse depress the horse's odds, imagine a single strategic bettor (the "insider", $N=1$ ) who estimates that horse 1 is more likely to win than according to the prevailing market odds (set by "outsiders"). Suppose that the outsiders are not placing any money on 1, while they are placing some money on the competing horse 2. By betting just one dollar, when horse 1 wins our bettor can be sure to obtain all the money bet by the outsiders on the other horses. Hence, the first dollar has a higher expected return than the second dollar, which has a zero marginal return. Since our bettor loses the dollar when horse 1 does not win the race, in this extreme example our bettor does not want to bet more than one dollar on horse 1 .

More generally, given the parimutuel payoff structure, the payout per dollar bet on horse 1 is decreasing in the fraction of money that is bet on horse 1 . Because the insider takes into account the payoff on all of his bets, it is optimal to cease betting before the payout on the marginal bet equates the marginal cost. This implies a bias, that our bettor does not bet until the market probability equals his posterior belief.

From the mathematical point of view, the bettor's problem is the same as the problem of a monopolist who decides how much quantity of a product to sell in a market with a downward sloping demand curve. Essentially, the parimutuel market structure induces such a downward sloping demand, because the average payout decreases in the amount wagered.

We now illustrate this explanation in the simplest possible setting, keeping $N=1$. Clearly, it is never optimal for our insider to bet on both horses. ${ }^{9}$ Suppose that the insider believes sufficiently more than the outsiders that horse 1 will win so that there is a positive gain from betting a little on it. Precisely, assume $q_{1}>b_{0}(1) /\left[B_{0}(1-\tau)\right]$. If bettor 1 bets the amount $b_{1}(1)=b$ on this horse, the price of each bet is determined on the basis of the inverse demand curve

$$
P(b)=\frac{q_{1}}{m}=(1-\tau) q_{1} \frac{B_{0}+b}{b_{0}(1)+b} .
$$

The insider's objective is to maximize the expected revenue $(P(b)-1) b$. The marginal revenue is $P(b)-1+P^{\prime}(b) b$. Our assumption that $q_{1}>b_{0}(1) /\left[B_{0}(1-\tau)\right]$ means precisely

\footnotetext{
${ }^{9}$ Isaacs (1953) shows more generally that a bettor should bet at most on all but one horse.
} 


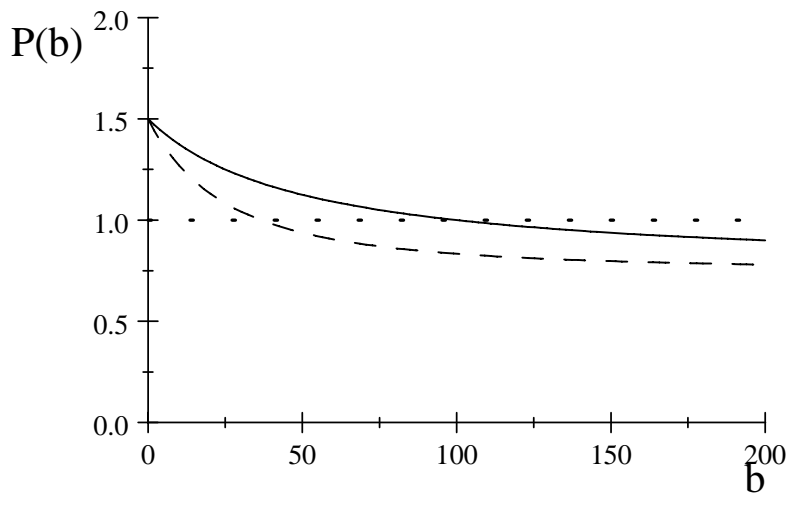

Figure 2: The optimal bet equalizes the marginal revenue (the dashed curve) to the unit marginal cost (the dotted line). The solid curve represents the demand.

that the marginal revenue evaluated at $b=0$ is positive, $P(0)>1$. The optimal positive bet size is then determined by the first order condition

$$
P(b)-1=-P^{\prime}(b) b \text {. }
$$

Since the demand curve is downward sloping, the right hand side is strictly positive, so we can conclude that the insider's optimal bet satisfies $P(b)>1$. This is clearly equivalent to $q_{1}>m$. If we additionally suppose that the insider is betting on the favorite ${ }^{10}$ and suppose that the insider's belief $q_{1}$ is correctly equal to $p$, we obtain the main result:

Proposition 2 Suppose that the insider bets on the favorite with correct beliefs. Then the favorite's market win chance is lower than the empirical chance: $p>m>1 / 2$.

Figure 2 displays the demand curve, the marginal revenue, and the marginal cost for an example with $B_{0}=100, b_{0}(1)=50, \tau=0, p=3 / 4$. It is possible to solve the insider's optimization problem for the optimal bet $b_{1}(1)=50(\sqrt{3}-1)=36.603$. The market probability is then $m(1)=b(1) / B=(3-\sqrt{3}) / 2=0.63397<3 / 4=p$.

Chadha and Quandt (1996) extended this explanation by considering the case with multiple bettors who play a Nash equilibrium. ${ }^{11}$

\footnotetext{
${ }^{10} \mathrm{~A}$ sufficient condition for outcome 1 being the favorite is that the outsiders have it as their favorite, $b_{0}(1) / B_{0} \geq 1 / 2$. Outcome 1 is also likely to become the favorite because the insider bets on it, so the condition is not necessary.

${ }^{11}$ On the way to derive the competitive limit with an infinitely many bettors, Hurley and McDonough (1995) also characterize the Nash equilibrium resulting with a finite number of bettors.
} 


\section{$5 \quad$ Preference for Risk}

The third explanation for the FLB is based on the different variability in the payout of a bet on a longshot compared to one on a favorite. Longshots tend to pay out more, but with smaller probability. If bettors prefer riskier bets, the relative price of longshots should be relatively higher. This explanation has first been spelled out by Weitzman (1965), followed by many others. ${ }^{12}$

Keeping with Weitzman (1965), we assume that there are many identical bettors, all with the same beliefs and risk preferences. Without loss of generality, normalize the mass of bettors to $N=1$. For simplicity, we further assume with Quandt (1986) that bettors have mean-variance preferences, $u=E-\rho V$, with coefficient of risk aversion equal to $\rho$. Each bettor is small relative to the size of the market, and so takes the market prices as given when deciding which of the two horses to back. Set $\tau=0$.

If horse 1 is the market favorite and attracts a fraction $m=m_{F}=1-m_{L}>1 / 2$ of the pool of parimutuel bets, it yields the expected net monetary payment

$$
E_{F}=\frac{p}{m_{F}}-1
$$

Similarly, the expected net monetary payment on the longshot is

$$
E_{L}=\frac{1-p}{m_{L}}-1
$$

The variance of the net monetary payment on the favorite is

$$
V_{F}=p\left(-1+\frac{1}{m_{F}}\right)^{2}+(1-p)(-1)^{2}-\left(\frac{p}{m_{F}}-1\right)^{2}=\frac{(1-p) p}{m_{F}^{2}} .
$$

Similarly, the variance of a bet on the longshot is

$$
V_{L}=p(-1)^{2}+(1-p)\left(-1+\frac{1}{m_{L}}\right)^{2}-\left(\frac{1-p}{m_{L}}-1\right)^{2}=\frac{(1-p) p}{m_{L}^{2}} .
$$

Note that $V_{L}>V_{F}$ because $m_{F}=1-m_{L}>1 / 2$ because by definition the favorite has a higher market probability.

In equilibrium, the following indifference condition must hold $E_{F}-\rho V_{F}=E_{L}-\rho V_{L}$, or equivalently

$$
-\rho=\frac{E_{F}-E_{L}}{V_{L}-V_{F}} .
$$

\footnotetext{
${ }^{12}$ Golec and Tamarkin (1998) advanced the related hypothesis that bettors love skewness, while being risk averse.
} 


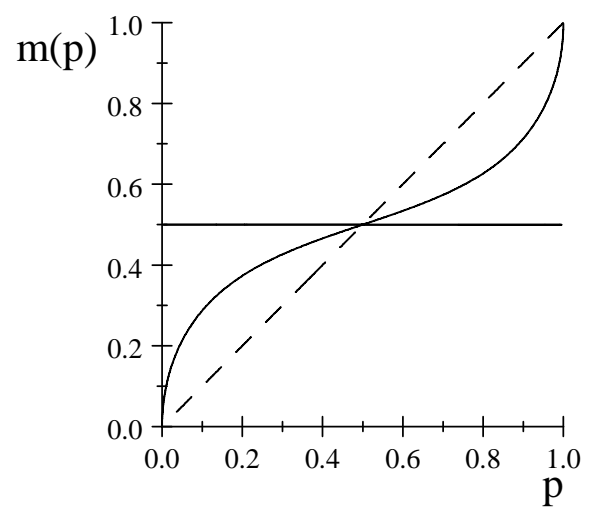

Figure 3: Market probability against objective probability for $\rho=-1$. The market probability is above the objective probability (represented by the dashed diagonal) for the favorite $(p>1 / 2)$. The pattern is reversed for the longshot $(p<1 / 2)$.

Now, if the representative bettor has a preference for risk $(\rho<0)$, at equilibrium we must have

$$
\frac{E_{F}-E_{L}}{V_{L}-V_{F}}>0
$$

Given that the denominator of the left hand side is positive $\left(V_{L}>V_{F}\right.$, as shown above), this inequality implies that $E_{F}-E_{L}>0$, i.e., that $m_{F}<p$ or, equivalently by $m_{F}=1-m_{L}$, that $1-p<m_{L}$. Combining these inequalities with $m_{F}=1-m_{L}>1 / 2$, we obtain the FLB: $1-p<m_{L}<1 / 2<m_{F}<p$.

Proposition 3 Suppose that there is zero track take, $\tau=0$, and a representative bettor with mean-variance preferences and negative coefficient of risk aversion, $\rho<0$. The market probability of the favorite (respectively longshot) is lower (respectively higher) than its objective probability: if $p>1 / 2$, then $1 / 2<m<p$ (respectively if $p<1 / 2$, then $p<m<1 / 2)$.

It is easy to further characterize the equilibrium in this setting. In equilibrium, each bettor must be indifferent between betting on the favorite and betting on the longshot,

$$
u_{F}=\frac{p}{m_{F}}-1-\rho \frac{(1-p) p}{m_{F}^{2}}=\frac{1-p}{1-m_{F}}-1-\rho \frac{(1-p) p}{\left(1-m_{F}\right)^{2}}=u_{L},
$$

where we have substituted (5), (6), (7), (8), and the identity $m_{L}=1-m_{F}$ into the indifference condition (9). This equation can be solved to obtain the equilibrium market 
probability as a function of the objective probability, $m(p)$. The inverse function $p(m)$ has the simpler analytic expression

$$
p(m)=\frac{1}{2}+\frac{\sqrt{[\rho(2 m-1)+m(1-m)]^{2}-4 \rho(2 m-1) m^{2}(1-m)}-m(1-m)}{-2 \rho(2 m-1)} .
$$

Figure 3 displays the market probability as a function of the objective probability for an example with $\rho=-1$.

Quandt (1986) further generalized this example by allowing for heterogeneous risk attitudes.

\section{Heterogeneous Beliefs}

Following Ali (1977), suppose that bettors have heterogeneous prior beliefs. Suppose that bettors do not observe any private signal, so that they do not have superior information. Suppose that the track take is zero, $\tau=0$, bettors are risk neutral, $u(w)=w$, have identical wealth available for betting, and have beliefs drawn from the same distribution, $q_{n} \sim F($.$) .$

It follows that each bettor bets all the available wealth on either of the two horses. The competitive equilibrium is characterized by the indifference threshold belief $\bar{q}$, at which the expected payoff from betting on either horse is equalized. Bettors with belief above threshold $\bar{q}$ bet on horse 1 and bettors with belief below $\bar{q}$ bet on horse 2 .

Proposition 4 (i) The market probability on the favorite is below the belief of the median bettor: If $m>1 / 2$, then $m<p$ where $p=F^{-1}(1 / 2)$. (ii) If in addition the belief of the median bettor is equal to the objective probability, then the market probability that the favorite wins is lower than the objective probability.

We focus on a horse whose market probability in the parimutuel system is

$$
m>1 / 2 \text {. }
$$

By definition, the fraction of all bets that are placed on this horse is equal to the market probability $m$. Note that a risk-neutral bettor optimally bets on the horse when subjectively believing that this horse is more likely to win than indicated by the market 
probability. So, it must be that the fraction of bettors who have subjective beliefs above $m$ is equal to the market probability,

$$
1-F(m)=m \text {. }
$$

By definition of the median $p$, half of the bettors have beliefs above it,

$$
1-F(p)=1 / 2 \text {. }
$$

Combining (10), (11), (12), and the property that the belief distribution $F$ is increasing, the market probability is below the median, $m<p$, as stated in part (i) of the proposition. Part (ii) follows immediately.

This result is a general implication of competitive equilibrium behavior, and holds independently of the parimutuel market structure. What drives this result is the fact that bettors are allowed to put at risk a limited amount of money. To see this, we now reinterpret the parimutuel equilibrium as the Walrasian equilibrium in a complete ArrowDebreu market. Traders are allowed to buy long positions or sell short positions on the asset that pays 1 conditional on horse 1 winning. Each trader is allowed (or desires) to lose at most an amount equal to 1 . This means that, when wishing to buy long the asset that is traded at price $m$, a trader purchases at most $1 / m$ asset units - by risk neutrality, this is the exact amount purchased. At price $m$, the demand curve for the asset is then $[1-F(m)] / m$. Similarly, a trader who wishes to sell short actually sells at most $1 /(1-m)$ asset units when the asset price is $m .{ }^{13}$ The asset's supply curve is then $F(m) /(1-m)$. The equilibrium price $m$ prevailing in the market equates demand and supply

$$
\frac{1-F(m)}{m}=\frac{F(m)}{1-m}
$$

which is equivalent to $(11) .{ }^{14}$

Intuitively, $m<p$ means that the median bettor (with belief $p$ ) strictly prefers to risk all their money on horse 1, by taking long positions. By continuity a bettor with a belief slightly more pessimistic is also long on horse 1 . If all traders were to invest the same amount on either horse, the market could not equilibrate because the demand for long

\footnotetext{
${ }^{13}$ The reason for this is that this trader's income on on the contracts sold is $-m /(1-m)$, while the trader's outlays are $1 /(1-m)$ when horse 1 wins. Overall, this trader risks $1 /(1-m)-m /(1-m)=1$.

${ }^{14}$ Eisenberg and Gale (1959) considered the properties of the parimutuel equilibrium price as an aggregation device for the heterogeneous beliefs.
} 


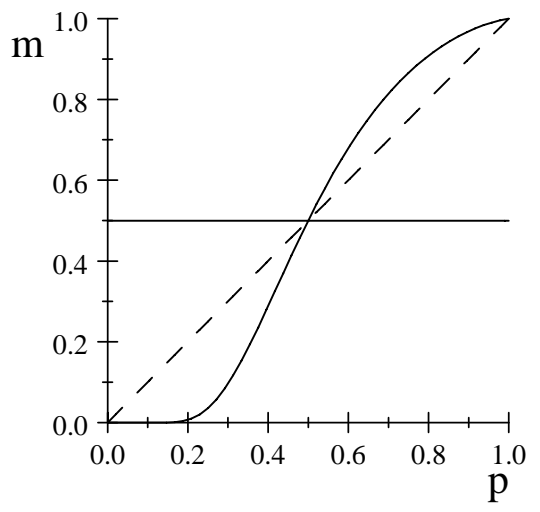

Figure 4: Plot of the median belief against the market probability. The dashed line is the diagonal.

positions would outstrip the supply at price $m$, given that $1-F(m)>F(m)$ for a price below the median, $m<p$. In equilibrium the number of assets bought is equal to the number of securities sold, so each trader on the long side must be allowed to buy less than each trader on the short side can sell, i.e., $m>1-m$.

Ali's result may be illustrated by this class of belief distributions $F_{\alpha}(q)=q^{\alpha}$, parameterized by $\alpha>0$. There is a one-to-one relationship between the parameter $\alpha>0$ and the equilibrium market probability $0<m<1$ solving (11), which can be expressed as $\alpha=[\log (1-m)] /[\log (m)]$. The median of $F_{\alpha}$ solving $(12)$ is $p=2^{-1 / \alpha}$. Figure 4 plots the median belief against the market probability. Note that the FLB results: If $m>1 / 2$ we have $1 / 2<m<p$, while if $m<1 / 2$ we have $1 / 2<p<m$.

Blough (1994) extended this result to an arbitrary number of horses under a natural symmetry assumption.

\section{Market Power by Uninformed Bookmaker}

We now turn to Shin's (1991 and 1992) explanation, based on the response of an uninformed bookmaker to the private information possessed by insiders. Shin mostly focused on the case of a monopolist bookmaker who sets odds in order to maximize profits. ${ }^{15}$

Shin (1991) considered the case of a bookmaker who faces a heterogeneous population

\footnotetext{
${ }^{15}$ Bookmakers play the role of market makers, as in Copeland and Galai (1983) and Glosten and Milgrom (1985). Shin, however, makes different assumptions about the relative elasticities of the demands of informed and uninformed traders.
} 
of bettors. Some bettors are informed insiders, while others are uninformed outsiders who have heterogeneous beliefs. The $N$ insiders are perfectly informed, so that they always pick the winning horse. In the absence of outsiders, the bookmaker would then be sure to make a loss at any finite price. In his model, the bookmaker is active thanks to the presence of outsiders, who play the role of noise traders. The outsiders are assumed to have beliefs distributed uniformly, with $q_{0} \sim U[0,1]$, and to have aggregate wealth $b_{0}$.

Shin first established that the bookmaker sets prices such that some outsiders find it most attractive to abstain from betting. This is a natural pre-condition for the bookmaker's ability to make any positive profit at all. For the purpose of our analysis, this partial abstention implies that we can consider odds-setting on one horse, say horse 1, in isolation.

A unit bet on the horse under consideration (i.e., a bet that pays 1 if horse 1 wins) will have price $m$ set by the bookmaker. ${ }^{16}$ Outsiders with beliefs above a unit bet's price place the bet. At price $m$, the outsiders' demand is then equal to $b_{0}(1-m)$.

The bookmaker believes that horse 1 wins with chance $q$. He chooses $m$ to maximize the profit

$$
-q\left[b_{0}(1-m)+N\right]\left(\frac{1-m}{m}\right)+(1-q) b_{0}(1-m) .
$$

The bookmaker believes that horse 1 wins with probability $q$, in which case the bookmaker makes a net payment equal to $(1-m) / m$ to $b_{0}(1-m)$ outsiders and to the insiders. If instead horse -1 wins, which happens with probability $1-q$, the bookmaker gains $b_{0}(1-m)$, the amount placed by the outsiders on horse 1 .

The monopolist bookmaker's first-order condition for choosing $m$ to maximize (13) is

$$
q\left(b_{0}(1-m)+N\right) \frac{1}{m^{2}}+b_{0} q\left(\frac{1-m}{m}\right)-b_{0}(1-q)=0,
$$

solved by

$$
m=\sqrt{\frac{q}{1-\frac{N}{b_{0}+N}}} .
$$

The fraction of the insiders' wealth over the total, $z=\frac{N}{b_{0}+N}$ is a measure of the amount of insider information in the market. While the market price $m$ is an increasing function of the bookmaker's belief $q$, now the average return to a bet on horse 1 is $q / m=\sqrt{(1-z) q}$ which is increasing in $q$. This is the FLB.

\footnotetext{
${ }^{16}$ In this setting, these prices do not sum to one. Market probabilities can nevertheless be obtained by dividing these prices by their sum.
} 
Proposition 5 If the bookmaker's belief is correct, $q=p$, market probabilities underreact to changes in $p$ as $m / p$ is decreasing in $p$ (and $m$ ).

Intuitively, the lower is the market price $m$, the fewer outsiders participate, and the greater the bookmaker chooses the bias ratio $q / m$ to protect against the adverse selection of bettors. In this setting, the effect vanishes if bookmaking is perfectly competitive. ${ }^{17}$ The market price $m$ then makes the profit of (13) equal to zero, a condition solved by $m=q /(1-z)$. In that case $m / q$ is constant so there is no FLB. ${ }^{18}$

\section{Limited Arbitrage}

Hurley and McDonough (1995) explained the FLB on the basis of limited arbitrage by informed bettors. ${ }^{19}$ Our illustration of this logic is similar to that in Section 4, except that there is now perfect competition among the insiders.

Suppose that very (or infinitely) many insiders know that the probability that horse 1 wins is $q=p>1 / 2$. Given that the number of insiders is large, it is reasonable to assume that they are price takers.

In the absence of transaction costs these insiders will place their bets such that the expected payoff on both horses are equal. Equating these two expected payoffs gives

$$
p \frac{B_{0}+B_{-0}}{b_{0}(1)+B_{-0}}=\frac{p}{m}=\frac{1-p}{1-m}=(1-p) \frac{B_{0}+B_{-0}}{b_{0}(2)},
$$

which determines the amount $B_{-0}$ bet by the insiders on horse 1 . In this case with zero track take, the equation implies $m=p$, so that there is no FLB.

Suppose now that the trace take is positive, $\tau>0$. Now the insiders will keep betting on the favorite, horse 1, only if the net expected payoff is non negative. Equating to zero the net expected payoff of betting on horse 1 ,

$$
(1-\tau) p \frac{B_{0}+B_{-0}}{b_{0}(1)+B_{-0}}=(1-\tau) \frac{p}{m}=1,
$$

we determine the amount $B_{-0}$ the insiders bet on horse 1 . If the insiders bet a positive amount, $m=p(1-\tau)<p$.

\footnotetext{
${ }^{17}$ However, Ottaviani and Sørensen (2005) show that the FLB results in a natural model with competitive fix-odds bookmakers, when insiders are partially (rather than perfectly) informed.

${ }^{18}$ In Shin (1992) the bookmaker solves a related constrained maximization problem. In an initial stage of bidding for the monopoly rights, the bookmaker has committed to a cap $\beta>0$ such that the implied market probabilities satisfy $\sum_{x \in \mathcal{X}} m(x) \leq \beta$. The FLB is derived along similar lines.

${ }^{19}$ See also Terrell and Farmer (1996).
} 
Proposition 6 Suppose that there is a positive track take, and an infinite number of insiders with correct common belief on horse 1, $p>1 / 2$. If they bet on horse 1 , its market probability is lower than the insider's probability, $m=p(1-\tau)<p$, and the expected payoff on the favorite is greater than on the longshot, $1>(1-\tau)(1-p) /[(1-p)+p \tau]$.

It is immediate to verify that the longshot's market probability is $1-m=1-p+p \tau$. The expected payoff is $(1-\tau)(1-p) /[(1-p)+p \tau]<1$. Because arbitrage is limited, relatively too many bets are placed on the longshot, and the bets placed on the favorite are not sufficient to bring up the expected return on the longshot to the same level as on the favorite. The track take thus induces an asymmetry in the rational bets, resulting in the FLB.

\section{Simultaneous Betting by Insiders}

Ottaviani and Sørensen (2006) proposed a purely informational explanation for the FLB in the context of parimutuel betting. To illustrate this explanation, we consider the simplest case in which the two horses are ex-ante equally likely to win $(q=1 / 2)$, the outsiders bets equal amounts on the two horses $\left(b_{0}(1)=b_{0}(2)=b_{0}\right)$, the track take is zero $(\tau=0)$, and the number of privately informed insiders is large (with mass $N$ ).

For the purpose of the starkest illustration of this explanation, focus on the case with a continuum of insiders. The conditional distributions of the insiders' initial beliefs are such that $G(r \mid x=2)>G(r \mid x=1)$ for all $0<r<1$, given that these beliefs contain information about the outcome of the race. Conditional on the outcome, the insiders' beliefs are independent. In addition, we make the natural assumption that these beliefs have symmetric distributions: $G(r \mid x=1)=1-G(1-r \mid x=2)$.

Since higher private beliefs are more frequent when horse 1 wins, in equilibrium each individual bets more frequently on horse $x$ in state $x$. For simplicity of exposition, suppose that all insiders choose to bet (even if they make negative profits). The equilibrium has a simple form, with bettors placing their bet on horse 2 with beliefs below a cutoff level and on horse 1 above the cutoff. Given that the outsiders' bets are balanced $\left(b_{0}(1)=b_{0}(2) \equiv\right.$ $b_{0}$ ), the cutoff of the posterior belief at which the expected payoff of a bet on horse 1 is equalized to the expected payoff of a bet on horse 2 is $\bar{r}=1 / 2$. 
Conditional on horse $x$ winning, the market probability for horse 1 is

$$
m=\frac{b_{0}+N[1-G(1 / 2 \mid x)]}{2 b_{0}+N} .
$$

Horse 1 has a higher market probability (i.e., is more favored) when state 1 is true,

$$
\frac{b_{0}+N[1-G(1 / 2 \mid 1)]}{2 b_{0}+N}>\frac{b_{0}+N[1-G(1 / 2 \mid 2)]}{2 b_{0}+N},
$$

given that $G(1 / 2 \mid 2)>G(1 / 2 \mid 1)$. This means that the identity of the winning horse, $x$, is fully revealed upon observation of the market probability. In this symmetric setting with a continuum of bettors, the horse with higher market probability, $m>1 / 2$, is revealed to be the sure winner, $p=1$ - and the horse with lower market probability, $m<1 / 2$, is revealed to be the sure loser, $p=0$. The market probabilities are always less extreme than the objective probabilities, hence the FLB:

Proposition 7 When there is a large number of privately informed bettors, equilibrium betting with parimutuel payoffs results in the FLB.

The bias would be reduced if bettors could instead adjust their positions in response to the final market distribution of bets (or, equivalently, the odds), as in a rational expectations equilibrium. ${ }^{20}$ However, the assumption that bettors observe the final odds is not realistic. Given that a large amount of bets are placed at the end of the betting period, the information on the final market odds is typically not available to bettors. The aggregate amounts bet are observable only after all bets have been placed. The explanation that we have exposed here is based on the fact that in a Bayes-Nash equilibrium the bettors do not observe the final distribution of bets.

For example, suppose that each bettor observes a signal with conditional distributions $F(s \mid 1)=s^{2}$ and $F(s \mid 2)=1-(1-s)^{2}$. This signal structure can be derived from a binary signal with uniformly distributed precision. With fair prior $q=1 / 2$, we have $r=s$ so that $G(r \mid 1)=r^{2}$ and $G(r \mid 2)=2 r-r^{2}$. Hence, conditional on horse 1 winning, the market probability for horse 1 is

$$
m=\frac{b_{0}+N[1-G(1 / 2 \mid x)]}{2 b_{0}+N}=\frac{b_{0}+(3 / 4) N}{2 b_{0}+N},
$$

\footnotetext{
${ }^{20}$ If the insiders have limited wealth, the FLB would only be fully eliminated in a rational expectations equilibrium.
} 
while the market probability for horse 2 is

$$
1-m=\frac{b_{0}+(1 / 4) N}{2 b_{0}+N}<m .
$$

Instead, conditional on the information revealed by the bets, the objective probability is 1 for horse 1 and 0 for horse 2 .

\section{Timing of Bets}

Ottaviani and Sørensen (2004) identified two countervailing incentives for timing bets in parimutuel markets:

- On the one hand, bettors have an incentive to place their bets early, in order to capture a good market share of profitable bets. This effect is best isolated when there is a small number of large bettors who share the same information. These bettors have the power to affect the odds, given that they have a sizeable amount of money.

- On the other hand, if bettors have private information, they have an incentive to delay their bets. As in open auction with fixed deadline, waiting allows the bettors to conceal their private information and maybe gain the information possessed by the other bettors. To abstract from the first effect, this second effect is best isolated when bettors are small and so have no market power.

\subsection{Early Betting}

If bettors are not concerned about revealing publicly their private information (for example because they have no private information), they have an incentive to bet early. As first observed by Isaacs (1953) and discussed in Section 4, with parimutuel betting the expected return on each additional dollar bet on horse 1 is decreasing in the amount the insider bets on this horse.

Next, consider what happens when there are two insiders. Suppose that there are two large strategic bettors, insider 1 and 2, who both think that horse 1 is more likely to win than horse 2. These bettors need to decide how much to bet and when to bet. For simplicity, suppose that there are just two periods, $t=1$ (early) and $t=2$ (late). We now 
show that both bettors will end up betting early in equilibrium. The reason for this is that each bettor prefers to bet early rather than late, because by being early a bettor can secure a higher payoff and steal profitable bets from the other bettor. Both bettors do so, and in equilibrium they end up betting both early.

Parimutuel betting among the two insiders is thus a special case of the classic Cournot (1838) quantity competition game. The result that betting takes place early is a corollary of Stackelberg's (1934) result that under quantity competition the first mover (or leader) derives higher payoff than the second mover (or follower). ${ }^{21}$

\subsection{Late Betting}

In addition to the incentive to bet early discussed above, Ottaviani and Sørensen (2004) also analyzed the incentive to bet late in order to conceal private information and maybe observe others, as in open auction with fixed deadline. This second effect is best understood by considering the case with small bettors without market power, but with private information.

Pennock's (2004) dynamic modification of the parimutuel payoff would further increase the incentive to bet early in the baseline model without private information. It would be interesting to characterize the timing incentives when there is private information and so bettors would normally have an incentive to bet late without Pennock's modification.

\footnotetext{
${ }^{21}$ Ottaviani and Sørensen (2004) extend this bet timing result to the case with more than two bettors.
} 


\section{References}

Ali, Mukhtar M., "Probability and Utility Estimates for Racetrack Bettors," Journal of Political Economy, 1977, 85(4), 803-815.

Blough, Stephen R., "Differences of Opinions at the Racetrack," in: Efficiency of Racetrack Betting Markets, edited by Donald B. Hausch, Victor S. Y. Lo, and William T. Ziemba, 1994, 323-341, Academic Press.

Borel, Émile, "Sur le Pari Mutuel," Comptes Rendus Hebdomadaires des Séances de l'Académie des Sciences, 1938, 207(3), 197-200.

Borel, Émile, Éléments de la Théorie des Probabilités, 1950, Paris: Albin Michel.

Chadha, Sumir and Richard E. Quandt, "Betting Bias and Market Equilibrium in Racetrack Betting," Applied Financial Economics, 1996, 6(3), 287-292.

Copeland, Thomas E. and Dan Galai, "Information Effects on the Bid-Ask Spread," Journal of Finance, 1983, 38(5), 1457-1469.

Cournot, Antoine A., Recherches sur les Principes Mathématiques de la Théorie des Richesses, 1838, Paris: Hachette.

Eisenberg, Edmund and David Gale, "Consensus of Subjective Probabilities: The PariMutuel Method," Annals of Mathematical Statistics, 1959, 30(1), 165-168.

Glosten, Lawrence and Paul Milgrom, "Bid, Ask and Transaction Prices in a Specialist Market with Heterogeneously Informed Traders," Journal of Financial Economics, 1985, 14(1), 71-100.

Golec, Joseph and Maurry Tamarkin, "Bettors Love Skewness, Not Risk at the Horse Track," Journal of Political Economy, 106(1), 1998, 205-225.

Griffith, R. M., "Odds Adjustment by American Horse-Race Bettors," American Journal of Psychology, 1949, 62(2), 290-294.

Hausch, Donald B. and William T. Ziemba, "Efficiency of Sports and Lottery Betting Markets," in: Handbook of Finance, edited by Robert A. Jarrow, Vojislav Maksimovic, and William T. Ziemba, 1995, North Holland Press. 
Hurley, William and Lawrence McDonough, "Note on the Hayek Hypothesis and the Favorite-Longshot Bias in Parimutuel Betting," American Economic Review, 1995, 85(4), 949-955.

Isaacs, Rufus, "Optimal Horse Race Bets," American Mathematical Monthly, 1953, 60(5), $310-315$.

Jullien, Bruno and Bernard Salanié, "Utility and Preference Estimation", Chapter 2 in Handbook of Investments, Volume 6: Efficiency of Sports and Lottery Betting Markets, edited by Donald B Hausch and William T. Ziemba, 2008, North Holland Press.

Ottaviani, Marco and Peter Norman Sørensen, "The Timing of Parimutuel Bets," 2004, London Business School and University of Copenhagen, mimeo.

Ottaviani, Marco and Peter Norman Sørensen, "Parimutuel versus Fixed-Odds Markets," 2005, London Business School and University of Copenhagen, mimeo.

Ottaviani, Marco and Peter Norman Sørensen, "Noise, Information, and the FavoriteLongshot Bias," 2006, London Business School and University of Copenhagen, mimeo.

Pennock, David M., “A Dynamic Pari-mutuel Betting Market for Hedging, Wagering, and Information Aggregation," ACM Conference on Electronic Commerce, 2004.

Prelec, Drazen, "The Probability Weighting Function," Econometrica, 1998, 66(3), 497527.

Quandt, Richard E., "Betting and Equilibrium," Quarterly Journal of Economics, 1986, 101(1), 201-207.

Sauer, Raymond D., "The Economics of Wagering Markets," Journal of Economic Literature, 1998, 36(4), 2021-2064.

Shin, Hyun Song, "Optimal Betting Odds Against Insider Traders," Economic Journal, 1991, 101(408), 1179-1185.

Shin, Hyun Song, "Prices of State Contingent Claims with Insider Traders, and the Favourite-Longshot Bias," Economic Journal, 1992, 102(411), 426-435.

Stackelberg, H., Marktform und Gleichgewicht, 1934, Vienna: Springer.

Terrell, Dek and Amy Farmer, "Optimal Betting and Efficiency in Parimutuel Betting Markets with Information Costs," Economic Journal, 1996, 106(437), 846-868. 
Thaler Richard H. and William T. Ziemba, "Anomalies: Parimutuel Betting Markets: Racetracks and Lotteries," Journal of Economic Perspectives, 1988, 2(2), 161-174.

Weitzman, Martin, "Utility Analysis and Group Behavior: An Empirical Analysis," Journal of Political Economy, 1965, 73(1), 18-26. 